\title{
Differences in the GH-IGF-I axis in children of different weight and fitness status
}

\author{
Peter A. Hosick ${ }^{a,}{ }^{,}$, Robert G. McMurray ${ }^{b}$, A.C. Hackney ${ }^{b}$, Claudio L. Battaglini ${ }^{b}$, Terry P. \\ Combs $^{\mathrm{C}}$, and Joanne S. Harrell ${ }^{\mathrm{d}}$ \\ aDepartment of Physiology and Biophysics, University of Mississippi Medical Center, Arthur C. \\ Guyton Research Complex, 2500 N State Street, Jackson, MS 39216-4505, United States
}

bDepartment of Exercise and Sport Science, 209 Fetzer Hall, CB\#8700, The University of North Carolina, Chapel Hill, NC 27599-8700, United States

'Department of Nutrition, 2002 Michael Hooker Research Center, School of Medicine and Gillings School of Global Public Health, The University of North Carolina at Chapel Hill, Chapel Hill, NC 27599-7461, United States

dDepartment of Adult and Geriatric Health, School of Nursing, CB \#7460, The University of North Carolina, Chapel Hill, NC 27599-7460, United States

\begin{abstract}
Objective-To determine if differences in the GH-IGF-I axis exist between children of high and low aerobic fitness who are obese or of normal weight.

Design-124 children (ages 8-11) divided into four groups based on BMI and $\mathrm{VO}_{2} \mathrm{max}\left(\mathrm{mL} \mathrm{O}_{2} /\right.$ $\mathrm{kg}$ fat free mass(FFM)/min): normal weight — high-fit (NH), normal weight — low-fit (NL), obese - high-fit $(\mathrm{OH})$, and obese — low-fit (OL). Height, weight, skinfolds, body mass index (BMI), body fat percentage and predicted $\mathrm{VO}_{2} \max$ (both $\mathrm{ml} / \mathrm{kg} / \mathrm{min}$ and $\mathrm{ml} / \mathrm{kg}_{\mathrm{FFM}} / \mathrm{min}$ ) were assessed. Resting growth hormone (GH), total insulin-like growth factor 1 (total IGF-I), free insulin-like growth factor 1(free IGF-I), and insulin were measured using morning fasting blood samples.
\end{abstract}

Results-GH was greater in the NH group compared to the OL group only ( $<<0.01)$. No group differences existed for either total IGF-I ( $\mathrm{p}=0.53)$ or free IGF-I ( $\mathrm{p}=0.189)$. Insulin was greater in the $\mathrm{OH}$ and $\mathrm{OL}$ groups than the $\mathrm{NH}$ and $\mathrm{NL}$ groups $(\mathrm{p}<0.01)$. With groups combined (or overall), insulin and free IGF-I were related to fitness (insulin $-\mathrm{ml} / \mathrm{kg} / \mathrm{min}$ : $\mathrm{r}=-0.226, \mathrm{p}<0.05$ and $\mathrm{ml} /$ $\mathrm{kg}_{\mathrm{FFM}} / \mathrm{min}: \mathrm{r}=-0.212, \mathrm{p}<0.05$; free IGF-I $-\mathrm{ml} / \mathrm{kg} / \mathrm{min}: \mathrm{r}=-0.219, \mathrm{p}<0.01$ and $\mathrm{ml} / \mathrm{kg}_{\mathrm{FFM}} / \mathrm{min}$ : $\mathrm{r}=-0.272, \mathrm{p}<0.05)$.

Conclusions-Fitness may contribute to the obesity related reduction of GH that may be involved with weight gain.

\section{Keywords}

Insulin; Fat free mass; $\mathrm{VO}_{2}$ max; Aerobic fitness; Youth

\footnotetext{
(C) 2012 Elsevier Ltd. All rights reserved.

*Corresponding author. Tel.: +1 601815 1366. phosick@umc.edu (P.A. Hosick).

Conflict of interest

Authors have no conflict of interest to report.
} 


\section{Introduction}

Obesity leads to a disruption of the GH-IGF-I axis such that GH is generally reduced [1-3]. Part of the disruption can be linked to the increased insulin that often accompanies obesity. Insulin increases the number of cell surface GH receptors, increasing hepatic tissue sensitivity to GH [4]. The result of increased hepatic GH sensitivity is a decreased amount of GH needed to stimulate IGF-I release. Elevated levels of insulin can also affect levels of free IGF-I by inhibiting some of the binding proteins for IGF-I [5-7]. While further research is needed to fully understand these complex interactions, data to date indicates obese children generally have low levels of resting GH and normal or slightly reduced levels of total IGF-I and free IGF-I [8,9]. However, there is very little data on free IGF-I and obesity or fitness in children.

In the USA, the most recent estimates show that $\sim 19 \%$ of all children age 6-19 are obese (defined as $\geq 95$ th percentile) [10]. Hormonal alterations of the GH-IGF-I axis in obesity may play a role in exacerbating weigh gain in overweight individuals because of the axis' involvement in fat utilization and muscle development [11,12]. Therefore, research exploring factors that potentially contribute to the problem of continued weight gain in children is needed. Additionally, research suggests that physical fitness in obese individuals can return the GH-IGF-I axis to a more normal state. Several intervention studies have shown increasing physical fitness, increases insulin sensitivity of obese children [13-16], which has the potential to impact the GH-IGF-I axis. Thus, the purpose of this investigation was to determine if differences exist in the GH-IGF-I axis of obese and normal weight children with high and low aerobic fitness using a matched-subjects design.

\section{Methods}

\subsection{Subjects}

Subjects were obtained from the Cardiovascular Health in Children III (CHIC III) study, Cohort 5 (J.S. Harrell, P.I.). The CHIC III study investigated metabolic syndrome and cardiovascular risk factors in youth from rural North Carolina. A total of 124 children were selected from the 1486 participants, based on their weight and fitness status. Prior to participation parents and children gave written consent and assent in accordance with the Institutional Review Board.

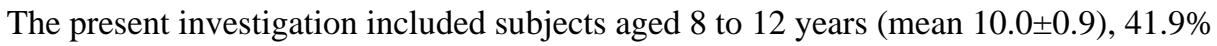
male, $58.1 \%$ female, $58.1 \%$ African American, $31.5 \%$ white, and $10.4 \%$ other races. Subjects were selected and divided into 4 groups based upon their weight and aerobic fitness $\left(\mathrm{VO}_{2} \max \right)$ status: normal weight high-fit $(\mathrm{NH})$, normal weight low-fit (NL), obese high-fit $(\mathrm{OH})$, and obese low-fit (OL). Normal weight was defined as $<85$ th and $>5$ th BMI percentile for age and sex. Obese was defined as $\geq 5$ th BMI percentile for age and sex. To obtain the sample for this study, the entire sample of 1486 subjects was first examined to find all the subjects that were obese and had high fitness levels ( $\mathrm{OH}$ group). All subjects in the $\mathrm{OH}$ group were then matched for sex, pubertal status with those youth who met the characteristics of the other three groups. When more than one match was available, the subject used for the analysis was randomly selected. Additionally, only children in tanner stage 1-3 were included in the final analysis in an attempt to remove as much of the pubertal associated alterations of the endocrine system as possible.

Aerobic fitness was determined based upon estimated fat free $\mathrm{VO}_{2}$ max expressed per unit of fat free mass $\left(\mathrm{mL} / \mathrm{kg}_{\mathrm{FFM}} / \mathrm{min}\right)$. This measurement was used in place of the more common $\mathrm{mL} / \mathrm{kg} / \mathrm{min}$ to account for the differing levels of adiposity between the groups. Using $\mathrm{VO}_{2}$ max expressed in units $\mathrm{mL} / \mathrm{kg}_{\mathrm{FFM}} / \mathrm{min}$ allows for comparison of oxygen uptake 
excluding body fat and is based more on metabolically active tissue; thus allowing for better comparisons of fitness between the subjects of different weight status [17]. Aerobic fitness levels were developed using data from 3235 CHIC subjects aged 8-12 collected from 1992 to 2005; the 33rd and 66th percentiles that were determined by age and gender are shown for males and females (Table 1). Subjects that had a $\mathrm{VO}_{2} \max \left(\mathrm{mL} / \mathrm{kg}_{\mathrm{FFM}} / \mathrm{min}\right)$ less than the 33 rd percentile were included in the low fitness group; those with a $\mathrm{VO}_{2} \mathrm{max}\left(\mathrm{mL} / \mathrm{kg}_{\mathrm{FFM}} /\right.$ min) greater than the 66th percentile were included in the high fitness group. The tertile distribution was used because it provided clearly definable groups and allowed for the largest sample of high-fit, obese subjects.

\subsection{Data collection procedures}

Complete details of the data collection procedures are presented elsewhere [18]. In summary, all data was collected in the subject's school during the school day with the exception of blood draws, which were collected in the morning. Height was measured using a standard calibrated stadiometer (Perspective Enterprises, Portage, MI) and body mass measured using a calibrated electronic scale (Model 2101KL, Healthometer Medical, Bridgewater. IL). Body mass index (BMI) was calculated using the standard formula: mass $(\mathrm{kg}) /$ height $(\mathrm{m})^{2}$. Skinfolds measured at the triceps and subscapula in triplicate [19] using calibrated Lange Skinfold calipers (Cambridge Scientific, Cambridge, MD) were used to estimate body fat percentages using sex and age specific formulas [20]. Fat free mass (FFM) was determined by subtracting predicted body fat percentage from one and multiplying by the subjects total body mass ( $\mathrm{kg}$ ). Pubertal status was estimated using the Pubertal Development Scale, a sex-specific, self-administered questionnaire with 5-item subscales [21].

Aerobic fitness $\left(\mathrm{VO}_{2} \max \right)$ was estimated using previously determined methods of McMurray et al. [22]. Heart rate was measured using a Polar Pacer heart rate monitor that was calibrated against an electrocardiogram. Calibrated cycle ergometers used included the BodyGuard (model 990), Tunturi magnetic-braked Tunuri Oy Ltd., (Turku, Finland), or a Monarch (model 818; Monark, Varberg, Sweden). Subjects pedaled the ergometer at a rate of $60 \mathrm{rpm}$ for three, 3-min stages. The workload during subsequent stages was increased by 30 to $60 \mathrm{~W}$, depending on the subject's age or heart rate at the end of the first stage. Heart rates were measured the last 10 seconds of each minute throughout the test. Heart rates measured during the last minute of each stage were used to extrapolate a physical work capacity (PWC). The PWC was converted to oxygen uptake (L/min) using equations established by McMurray et al. [22]. which produced an $\mathrm{r}=0.80$ with measured $\mathrm{VO}_{2}$ max.

The $\mathrm{VO}_{2}$ max per kilogram of fat free mass $\left(\mathrm{VO}_{2} \mathrm{FFM}\right)$ was determined from estimations of body fat percentage and absolute $\mathrm{VO}_{2}$ max. Fat free mass (FFM) was determined as indicated above. Finally, the subjects FFM was divided by absolute $\mathrm{VO}_{2}$ max giving the unit $\mathrm{mL}$ of $\mathrm{O}_{2}$ per kilogram of fat free mass per min $\left(\mathrm{VO}_{2} \mathrm{FFM}\right)$. For comparison with other studies, $\mathrm{VO}_{2}$ max was also predicted in units of millimeters of oxygen per kilogram total body mass $\left(\mathrm{VO}_{2} \mathrm{~kg}\right)$.

\subsection{Blood analysis}

Subjects were called the day before and reminded not to eat anything and drink only water until after the blood draw. Upon arrival the next morning subjects confirmed they fasted. All blood samples were obtained using the antecubital space of the arm of the subject's preference. Samples were immediately centrifuged and separated into individual mircocentrifuge tubes with $\sim 0.5 \mathrm{ml}$ plasma per tube. Samples were then placed on dry ice and transported to our laboratory where they were stored at $-80{ }^{\circ} \mathrm{C}$ until analysis. 
All blood analysis used commercially available assay kits. Serum total GH values were determined using ELISA technique (IBL-America, Minneapolis, MN). The intra-assay coefficient of variation (CV) for GH was 6.1\%; with an inter-assay CV of 4.0\%. The sensitivity reported from IBL-America was $0.2 \mathrm{ng} / \mathrm{mL}$, with a detection limit $1.25 \mathrm{ng} / \mathrm{mL}$. Total IGF-I (total IGF-I) values were measured using ELISA technique (R\&D System Laboratories (Minneapolis, MN). The sensitivity of the total IGF-I assay was reported as $0.026 \mathrm{ng} / \mathrm{mL}$, with a detection limits of $0.28 \mathrm{ng} / \mathrm{mL}$. The intra-assay CV for total IGF-I was $3.7 \%$; with an inter-assay CV of $4.1 \%$. Free IGF-I (free IGF-I) concentration was determined in plasma using ELISA technique (Diagnostics Systems Laboratories, Webster, TX) and had a sensitivity $0.015 \mathrm{ng} / \mathrm{mL}$ and a detection limit of $0.12 \mathrm{ng} / \mathrm{mL}$. The intra-assay CV for free IGF-I was 4.3\%; while the inter-assay CV was reported as $10.2 \%$. Plasma insulin levels were determined in duplicate using a commercially available kit (Linco, St. Charles, Mo., USA). Linco reports a $0.02 \%$ cross-reactivity with proinsulin, glucagon, somatostatin, IGF-1 or pancreatic polypeptide. Our CV between duplicate samples was less than $8 \%$ for measured insulin values.

\subsection{Statistical analysis}

Means and SEM were computed for all variables by group (NH, NL, OH, and OL). Analysis of variance (ANOVA) was conducted for GH, total IGF-I and free IGF-I to determine if hormone levels were different based on sex or race. For hormones that were significantly different by sex or race, an analysis of co-variance (ANCOVA) was used to control for these differences. If there were no sex and or race differences an ANOVA was used to determine differences by group. When the ANCOVA or ANOVA analyses showed significant group differences a Tukey post-hoc test was applied to compare specific means. To further explore any inter-relationships of the hormones combining all groups partial Spearman correlations were run between the hormonal concentrations and measures of fitness $\left(\mathrm{VO}_{2} \mathrm{FFM}\right.$ and $\mathrm{VO}_{2} \mathrm{~kg}$ ). Spearman correlations were run because normality of our measures could not be assumed due to the polarity involved in the group selection. Spearmen partial correlations adjusting for differences body fat percentage were run. Body fat percentage was adjusted for by adding it to the model first to account of any influence that body fat may have on these relationships. The alpha level was set at $\mathrm{p}<0.05$. All statistical analysis was computed using SAS version 9.1 (Cary, NC).

\section{Results}

\subsection{Group characteristics}

The group characteristics are found in Table 2 . The groups did not differ significantly by age, sex, race or pubertal status. Consistent with sample selection both obese groups had significantly greater height, mass, BMI, BMI percentile, fat percentage and fat free mass, compared to the $\mathrm{NH}$ group. Furthermore, regardless of fitness status obese groups were taller than the normal weight groups, in particular, the NH group. Both high-fit groups had significantly elevated $\mathrm{VO}_{2} \mathrm{FFM}$ compared to the low fitness groups. The $\mathrm{VO}_{2} \mathrm{~kg}$ was significantly different between all groups in the following order from highest to lowest: $\mathrm{NH}$, $\mathrm{NL}, \mathrm{OH}$, and $\mathrm{OL}$.

\subsection{Group comparisons of hormones}

The results of the ANOVA test to determine if hormones were different across gender and race showed that total and free IGF-I were elevated in African Americans compared to whites (total IGF-I: $\mathrm{p}=0.0300$; free IGF-I: $\mathrm{p}=0.0003$ ) and in boys compared to girls (total IGF-I: $\mathrm{p}=0.0001$; free IGF-I: $\mathrm{p}=0.0001$ ) but there were no sex or race differences in GH or insulin. Thus, an ANCOVA adjusting for sex and race was used for total and free IGF-I whereas ANOVA was used for GH and insulin. 
Growth hormone was significantly elevated in the NH group compared to the OL group (Fig. 1A). No differences were found between the other groups. Total IGF-I, after controlling for differences in gender and race, was not significantly different between any of the four groups ( $\mathrm{p}=0.5300$; Fig. 1B). Free IGF-I was not significantly different between any of the groups after controlling for gender and race ( $\mathrm{p}=0.1890$; Fig. 1C). Insulin was significantly lower in the $\mathrm{NH}$ and $\mathrm{NL}$ group than in the $\mathrm{OH}$ and $\mathrm{OL}$ groups, but did not differ between the high and low-fit groups (Fig. 1D).

\subsection{Relationships between hormones and fitness variables}

Overall (all groups combined) partial spearman correlations adjusting for difference in body fat percentage are reported in Table 3. Insulin was significantly correlated to free IGF-I, $\mathrm{VO}_{2} \mathrm{FFM}$ and $\mathrm{VO}_{2} \mathrm{~kg}$. Both total IGF-I and free IGF-I had a significant relationship with $\mathrm{GH}$, but only free IGF-I was related to the aerobic fitness measures.

\section{Discussion}

Alterations to the GH-IGF-I axis in obesity are well recognized in the literature [1-3]. These alterations have mechanistic links to those seen in both insulin insensitivity and obesity [57]. Studies that have shown improved fitness in obese individuals have also shown improvements to insulin sensitivity that may be favorable for normal functioning of the GHIGF-I axis [23-27]. This study was designed to examine the relationship between fitness, obesity and the GH-IGF-I axis. Our results suggest that having a higher $\mathrm{VO}_{2} \max$ in obesity does not protect against commonly associated reductions to insulin sensitivity, but may diminish some of the obesity related reduction of GH in children.

Children in the OL group had significantly lower GH compared to the NH group, GH levels did not differ between the $\mathrm{OH}$ and normal weight groups. However, further assessment of Fig. 1A shows mean GH level of the NL and $\mathrm{OH}$ groups were non-significantly lower compared to the NH group. Thus, a high fitness level may somehow maintain GH levels. The lower GH in the OL group was expected due to the elevated levels of insulin also present, which can increase the sensitivity of hepatic tissue to GH [4]. If the relationship between fitness and $\mathrm{GH}$ was driven by insulin alone, then the $\mathrm{OH}$ group should have significantly lower levels of $\mathrm{GH}$ as well, given that the $\mathrm{OH}$ and $\mathrm{OL}$ groups had similar resting insulin.

The non-significant reduction of $\mathrm{GH}$ in the $\mathrm{OH}$ group may have been due to their greater fitness level; yet, a significant association between GH and fitness was not found. Perhaps the combination of fitness and insulin level diminished the reduction of GH, as fitness has a significant negative correlation with insulin. However, a posteriori analysis correlating GH with $\mathrm{VO}_{2} \mathrm{FFM}$ and insulin did not show a significant relationship $(\mathrm{p}=0.38)$. Thus, we are unable to definitively explain why the $\mathrm{GH}$ values are not significantly lower in the $\mathrm{OH}$ group but we are confident that the level of fatness is what is driving the trend.

The effect obesity has on free or total IGF-I in adults is not in agreement or necessarily applicable to children as sex hormones system, which are not yet fully developed, have the potential to interact with the GH-IGF-I system $[28,29]$. In the present study statistical significance was not observed between the $\mathrm{OH}$ and $\mathrm{NH}$ groups for $\mathrm{GH}$, neither total nor free IGF-I were significantly different in any group, despite differences in fitness or weight status. Due to the relatively high concentration of total IGF-I with a low level of GH at rest, the small reduction in total IGF-I was not statistically, nor likely physiologically significant. A lack of change in total IGF-I is in agreement with several other investigations regarding obesity and fitness in adolescents $[8,9,23]$. There is little data on free IGF-I in children, but differences between normal and obese adolescents have been examined by Eliakim et al. [9]. 
who reported that total IGF-I of the obese subjects was less than that of the normal weight subjects, however free IGF-I was not reduced. The lack of a difference of free IGF-I in the present study may be partially explained by differences insulin, as it was elevated in the $\mathrm{OH}$ and OL groups and correlated to free IGF-I and fitness. Insulin can reduce some of the IGF-I binding proteins [25] (IGF-I binding proteins 1 and 2); however, these binding proteins make up only a small fraction of all the IGF-I binding proteins in circulation, thus alterations of free IGF-I are not statistically significant.

Despite the lack of significant group differences in free IGF-I there was a significant negative association between free IGF-I and both measures of fitness. This association suggests that free IGF-I may be lower in those with a high fitness level, who also have generally lower insulin levels. Given the possible influence that insulin has to increase free IGF-I by reducing IGF binding proteins [5-7], this association is logical. Thus, increased fitness even in obesity may allow for a more normal GH-IGF-I axis. Eliakim et al. [26]. suggested that there may be a threshold level for adiposity required to alter the GH-IGF-I axis. Perhaps if we had included overweight $(85-<95$ th percentile) as well as obese subjects ( $₫ 95$ th percentile) we would have been able to better examine this proposed threshold and the effect of fitness on it and the GH-IGF-I axis. However, when compared to the NH group the $\mathrm{OH}$ group did not have significantly reduced $\mathrm{GH}$, but the OL group did; hence our data suggest that improved fitness may increase the BMI threshold needed to have an effect on $\mathrm{GH}$. If this is the case, it has potential implications for the design of weight loss interventions such as exercise programs designed to improve aerobic fitness and not solely focused on energy expenditure.

The current investigation is not without limitations. Our estimation of $\mathrm{VO}_{2} \mathrm{max}$ is a limitation of this study. However collecting reliable $\mathrm{VO}_{2}$ max data on children in a school setting is a universal problem [27], especially with obese children, so estimations were used. Nevertheless our methods for predicting $\mathrm{VO}_{2}$ max has a strong correlation $(\mathrm{r}=0.80)$ to measured $\mathrm{VO}_{2} \max$ [22]. The use of skinfolds to predict body fat and not a more precise measure (e.g. DEXA) that would have provided more accurate data as well as body fat distribution information is another potential limitation. However, we were able to attain large differences between the group, suggesting that our distribution, although not precise, was appropriate. In addition, skinfolds were measured by trained staff and done in triplicate in accordance with NHANES recommendations [19]; thus we believe the data is reliable. Another limitation is that FFM is not a direct measure of muscle mass. However, using FFM does theoretically eliminate fat mass and focuses more on metabolically active tissue which may better reflect the capacity of the muscle, our results at present do not suggest that using $\mathrm{VO}_{2} \mathrm{FFM}$ is preferred over using $\mathrm{VO}_{2} \mathrm{~kg}$. Measurements of the individual IGF-I binding protein would have been helpful for interpretation of the results, but unfortunately this was not possible. Finally, the single measurement of GH is a limitation; however this study is believed to be the first to investigate the simultaneous relationships between obesity, fitness, and the GH-IGF-I axis. More frequent GH-IGF over a $24 \mathrm{~h}$ period with a larger, more homogeneous sample of children can improve the precision of the single-sample findings and clear up any discrepancies in the literature.

In conclusion, we have demonstrated through cross-sectional analysis that aerobically fit obese adolescents may have more normal GH levels than low-fit obese adolescents. However, the high level of aerobic fitness alone does not prevent the reduced insulin sensitivity often seen in obesity. Going forward strategies aimed at improving insulin sensitivity by weight reduction through diet and exercise may have more of an impact then improving fitness alone at maintaining GH levels. Thus, our data suggests that the effect of high levels of adiposity countermand much of the effect that high fitness normally may otherwise have because high fitness does not alone ameliorate the GH reduction. We believe 
these results to be important because the reduced GH level of obese low-fit children has the potential to be involved in weight gain as GH can increase oxidation of both carbohydrate and fatty acids for oxidation to fuel protein synthesis [12,29]. However, an important note of caution needs to be stated as at present we have only shown that a single fasting measurement of GH is reduced. Exploring pulsatile release of GH in similar populations over time would provide further evidence. Thus, future research examining fitness level and long term changes in weight status and adiposity may provide more insights to the possible relationships highlighted by this investigation.

\title{
Acknowledgments
}

\author{
Role of funding source \\ Partially funded by NIH NINR01837.
}

\section{References}

1. Maccario M, Gauna C, Procopio M, et al. Assessment of GH/IGF-I axis in obesity by evaluation of IGF-I levels and the GH response to GHRH+arginine test. J Endocrinol Invest. 1999; 6:424-429. [PubMed: 10435851]

2. Rasmussen MH, Juul A, Kjems LL, Skakkebaek NE, Hilsted J. Lack of stimulation of 24-hour growth hormone release by hypocaloric diet in obesity. J Clin Endocrinol Metab. 1995; 80:796-801. [PubMed: 7533771]

3. Veldhuis JD, Iranmanesh A, Ho KK, Waters MJ, Johnson MI, Lizzarralde G. Dual defects in pulsatile growth hormone secretion and clearance subserve the hyposomatotropism of obesity in man. J Clin Endocrinol Metab. 1991; 72:51-59. [PubMed: 1986027]

4. Leung KC, Doyle N, Ballesteros M, Waters MJ, Ho KK. Insulin regulation of human hepatic growth hormone receptors: divergent effects on biosynthesis and surface translocation. J Clin Endocrinol Metab. 2000; 85:4712-4720. [PubMed: 11134133]

5. Frystyk J, Skjaerbaek C, Vestbo E, Fisker A, Ørskov H. Circulating levels of free insulin-like growth factors in obese subjects: the impact of type 2 diabetes. Diabetes Metab Res Rev. 1999; 15:314-322. [PubMed: 10585616]

6. Nam SY, Lee EJ, Kim KR, et al. Effect of obesity on total and free insulin like growth factor (IGF)-1, and their relationship to IGF-binding protein (BP)-1, IGFBP-2, IGFBP-3, insulin, and growth hormone. Int J Obes. 1997; 21:355-359.

7. Nyomba BL, Berard L, Murphy LJ. Free insulin-like growth factor I (IGF-I) in healthy subjects: relationship with IGF binding proteins and insulin sensitivity. J Clin Endocrinol Metab. 1997; 82:2177-2181. [PubMed: 9215291]

8. Kamoda T, Saitoh H, Inudoh M, Miyazaki K, Matsui A. The serum levels of proinsulin and their relationship with IGFBP-1 in obese children. Diabetes Obes Metab. 2006; 8:192-196. [PubMed: 16448523]

9. Eliakim A, Nemet D, Zaldivar F, McMurray RG, Culler FL, Galassetti P, Cooper DM. Reduced exercise-associated response of GH-IGF-1 axis and catecholamines in obese children and adolescents. J Appl Physiol. 2006; 100:1630-1637. [PubMed: 16373448]

10. Ogden CL, Carroll MD, Curtin LR, Lamb MM, Flegal KM. Prevalence of high body mass index in US children and adolescents, 2007-2008. JAMA. 2010; 303:242-249. [PubMed: 20071470]

11. Alexopoulou O, Abs R, Maiter D. Treatment of adult growth hormone deficiency: who, why and how? A review. Acta Clin Belg. 2010; 65:13-22. [PubMed: 20373593]

12. Vijayakumar A, Novosyadlyy R, Wu Y, Yakar S, LeRoith D. Biological effect of growth hormone on carbohydrate and lipid metabolism. Growth Horm IGF Res. 2010; 20:1-7. [PubMed: 19800274]

13. Bell LM, Watts K, Siafarikas A, et al. Exercise alone reduces insulin resistance in obese children independently of changes in body composition. J Clin Endocrinol Metab. 2007; 92:4230-4235. [PubMed: 17698905] 
14. Chang C, Liu W, Zhao X, Li S, Yu C. Effect of supervised exercise intervention on metabolic risk factors and physical fitness in Chinese obese children in early puberty. Obes Rev. 2001; 9(Suppl 1):135-141. [PubMed: 18307716]

15. Landt KW, Campaigne BN, James FW, Sperling MA. Effects of exercise training on insulin sensitivity in adolescents with type I diabetes. Diabetes Care. 1985; 8:461-465. [PubMed: 4053932]

16. Nassis GP, Papantakou K, Skenderi K, et al. Aerobic exercise training improves insulin sensitivity without changes in body weight, body fat, adiponectin, and inflammatory markers in overweight and obese girls. Metabolism. 2005; 54:1472-1479. [PubMed: 16253636]

17. McMurray RG, Hosick PA, Bugge A. Importance of proper scaling of aerobic power when relating to cardiometabolic risk factors in children. Ann Hum Biol. 2011; 38:647-654. [PubMed: 21749316]

18. McMurray RG, Bauman MJ, Harrell JS, Brown S, Bangdiwala SI. Effects of improvement in aerobic power on resting insulin and glucose concentrations in children. Eur J Appl Physiol. 2000; 81:132-139. [PubMed: 10552278]

19. National Health Examination Survey. Publication \#74-1614. Department of Health, Education, and Welfare (DHEW); 1974. Vital and Health Statistics; p. 2-3.Series 11

20. Slaughter MH, Lohman TG, Boileau RA, Horswill CA, Stillman RJ, Van Loan MD, Bemben DA. Skinfold equations for estimation of body fatness in children and youth. Hum Biol. 1988; 60:709723. [PubMed: 3224965]

21. Petersen AC, Crockett L, Richards M, Boxer A. A self-report measure of pubertal status: reliability, validity and initial norms. J Youth Adolesc. 1988; 17:117-133.

22. McMurray RG, Guion WK, Ainsworth BE, Harrell JS. Predicting aerobic power in children. J Sports Med Phys Fitness. 1998; 38:227-233. [PubMed: 9830830]

23. Ubertini G, Grossi A, Colabianchi D, et al. Young elite athletes of different sport disciplines present with an increase in pulsatile secretion of growth hormone compared with non-elite athletes and sedentary subjects. J Endocrinol Invest. 2008; 31:138-145. [PubMed: 18362505]

24. Birzniece V, Meinhardt UJ, Umpleby MA, Handelsman DJ, Ho KK. Interaction between testosterone and growth hormone on whole-body protein anabolism occurs in the liver. J Clin Endocrinol Metab. 2011; 96:1060-1067. [PubMed: 21239519]

25. Ho KK, Gibney J, Johannsson G, Wolthers T. Regulating of growth hormone sensitivity by sex steroids: implications for therapy. Front Horm Res. 2006; 35:115-128. [PubMed: 16809927]

26. Holden JP, Butzow TL, Laughlin GA, Ho M, Morales AJ, Yen SC. Regulation of insulin-like growth factor binding protein-1 during the 24-hour metabolic clock and in response to hypoinsulinemia induced by fasting and Sandostatin in normal women. J Soc Gynecol Investig. $1995 ; 2: 38-44$.

27. Eliakim A, Scheett TP, Newcomb R, Mohan S, Cooper DM. Fitness, training, and the growth hormone $\rightarrow$ insulin-like growth factor I axis in prepubertal girls. J Clin Endocrinol Metab. 2001; 86:2797-2802. [PubMed: 11397890]

28. Cunningham DA, MacFarlane Van Waterschoot B, Paterson DH, Lefcoe M, Sangal SP. Reliability and reproducibility of maximal oxygen uptake measurements in children. Med Sci Sports. 1977; 9:104-108. [PubMed: 895425]

29. LeRoith D, Yakar S. Mechanisms of disease: metabolic effects of growth hormone and insulin-like growth factor 1. Nat Clin Pract Endocrinol Metab. 2007; 3:302-310. [PubMed: 17315038] 

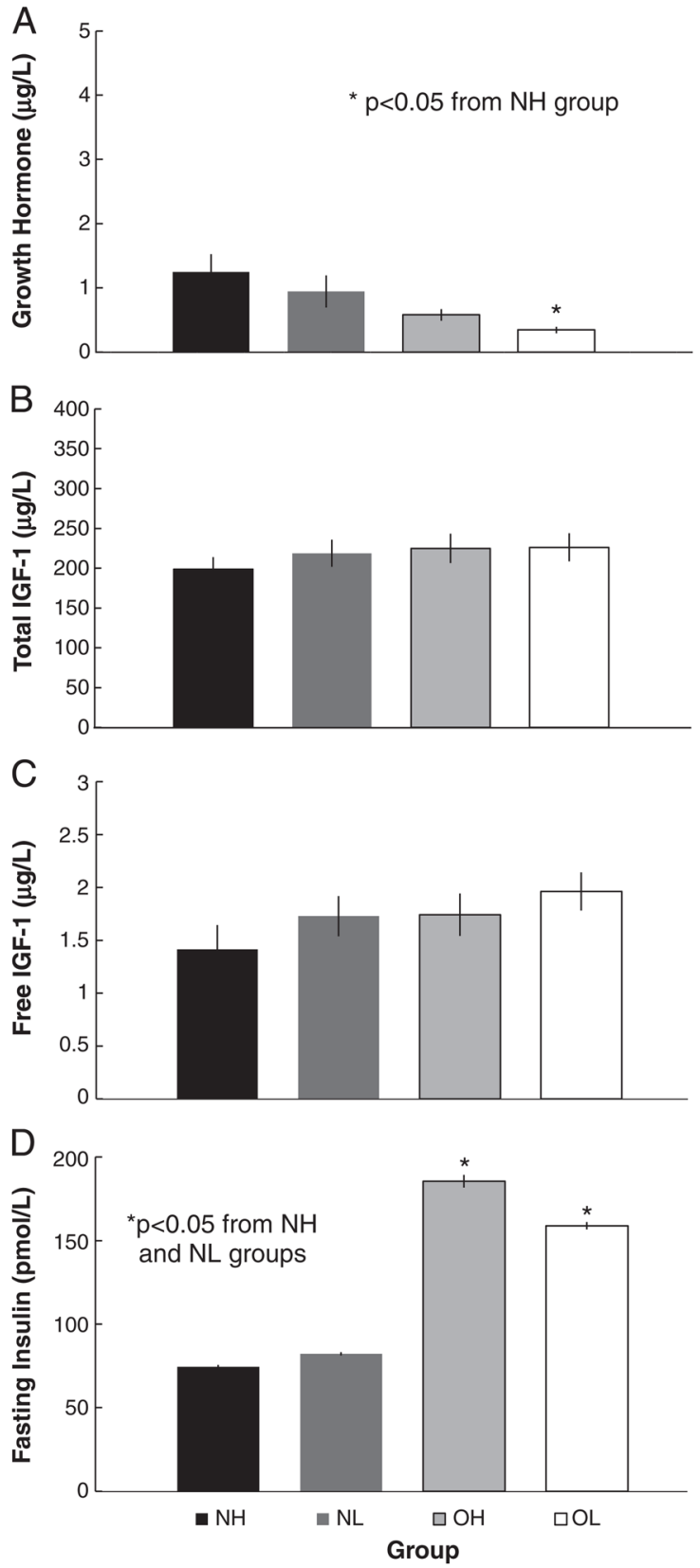

Fig. 1.

Mean $( \pm$ SEM) of $(\mathrm{A})$ resting growth hormone level (B) resting total insulin-like growth factor, (C) resting total insulin-like growth factor, and (D) fasting insulin level of the normal weight high-fit $(\mathrm{NH})$, normal weight low-fit $(\mathrm{NL})$, obese high-fit $(\mathrm{OH})$, and obese low-fit (OL) groups. 


\section{Table 1}

The 33rd\% (low-fit) and 66th\% (high-fit) cut-points of the presented by gender and age.

\begin{tabular}{lllll}
\hline Gender & $\mathbf{n}$ & Age & Fitness 33rd\% $\left(\mathbf{m L} / \mathbf{k g}_{\mathbf{F F M}} / \mathbf{m i n}\right)$ & Fitness 66th\% $\left(\mathbf{m L} / \mathbf{k g}_{\mathbf{F F M}} / \mathbf{m i n}\right)$ \\
\hline Male & 357 & 8 & 51.8 & 59.3 \\
Female & 420 & 8 & 49.9 & 58.7 \\
Male & 467 & 9 & 52.4 & 59.8 \\
Female & 453 & 9 & 49.8 & 57.1 \\
Male & 413 & 10 & 49.2 & 57.8 \\
Female & 357 & 10 & 46.0 & 53.8 \\
Male & 205 & 11 & 47.8 & 55.7 \\
Female & 188 & 11 & 43.4 & 50.4 \\
Male & 192 & 12 & 47.1 & 53.2 \\
Female & 183 & 12 & 45.5 & 52.0 \\
\hline
\end{tabular}


Table 2

Mean \pm standard deviation of anthropometric and fitness variables presented by group.

\begin{tabular}{|c|c|c|c|c|}
\hline & Normal high fitness & Normal low fitness & Obese high fitness & Obese low fitness \\
\hline $\mathrm{N}$ & 31 & 31 & 31 & 31 \\
\hline Sex (female, male) & 13,18 & 13,18 & 13,18 & 13,18 \\
\hline Race (AA, W, O) & $19,8,4$ & $20,7,4$ & $13,16,2$ & $20,8,3$ \\
\hline Age (years) & $9.9 \pm 0.9$ & $10.1 \pm 1.0$ & $10.1 \pm 0.8$ & $10.0 \pm 0.9$ \\
\hline Tanner stage & $2.2 \pm 0.7$ & $2.3 \pm 0.7$ & $2.3 \pm 0.7$ & $2.3 \pm 0.7$ \\
\hline Height $(\mathrm{cm})$ & $139 \pm 8.1^{\dagger} \tau^{t}$ & $143 \pm 9.3$ & $147 \pm 9.4^{*}$ & $148 \pm 9.1^{*}$ \\
\hline Body mass (kg) & $33.9 \pm 5.2^{\dagger t}$ & $36.7 \pm 6.5 \%$ & $60.9 \pm 17.4^{* \#}$ & $61.2 \pm 11.2^{* \#}$ \\
\hline BMI $\left(\mathrm{kg} / \mathrm{m}^{2}\right)$ & $17.4 \pm 5.7^{\dagger \%}$ & $17.6 \pm 1.7^{\dagger \%}$ & $27.7 \pm 4.9^{* \#}$ & $27.7 \pm 3.4^{* \#}$ \\
\hline BMI percentile & $53.2 \pm 20.8^{\dagger t}$ & $56.8 \pm 24.0 \%$ & $97.8 \pm 1.5^{* \#}$ & $98.1 \pm 1.2^{* \#}$ \\
\hline Body fat percentage & $17.4 \pm 5.7^{\dagger t}$ & $16.0 \pm 6.6^{\dagger t}$ & $36.7 \pm 11.0^{* \#}$ & $32.2 \pm 7.3^{* \#}$ \\
\hline Fat free mass $(\mathrm{kg})$ & $27.9 \pm 4.1^{\dagger \%}$ & $30.8 \pm 5.4 \%$ & $37.1 \pm 7.4^{* \#}$ & $40.9 \pm 6.0^{* \#}$ \\
\hline HOMA-IR & $2.3 \pm 1.4^{\dagger t}$ & $2.6 \pm 1.3^{f * t}$ & $5.8 \pm 4.6^{* \#}$ & $5.1 \pm 3.0 * \#$ \\
\hline $\mathrm{VO}_{2} \mathrm{FFM}\left(\mathrm{mL} / \mathrm{kg}_{\mathrm{FFM}} / \mathrm{min}\right)$ & $62.1 \pm 8.1 \%$ & $35.4 \pm 6.6^{t^{*}}$ & $64.8 \pm 10.3$ & $35.1 \pm 6.6^{t^{*}}$ \\
\hline $\mathrm{VO}_{2} \mathrm{~kg}(\mathrm{~mL} / \mathrm{kg} / \mathrm{min})$ & $51.3 \pm 7.5^{\#+\%}$ & $29.8 \pm 6.4^{*+* t}$ & $40.8 \pm 9.0^{* \# *}$ & $23.9 \pm 5.6^{* \# \dagger}$ \\
\hline
\end{tabular}

$\mathrm{AA}=$ African American, $\mathrm{W}=$ White, $\mathrm{O}=$ Other races, HOMA-IR $=$ homeostatic model assessment - insulin resistance.

*

$\mathrm{p}<0.05$ from $\mathrm{NH}$,

${ }^{\#}$ p $<0.05$ from NL,

${ }^{\dagger} \mathrm{p}<0.05$ from $\mathrm{OH}$,

${ }_{\mathrm{p}}<0.05$ from OL. 


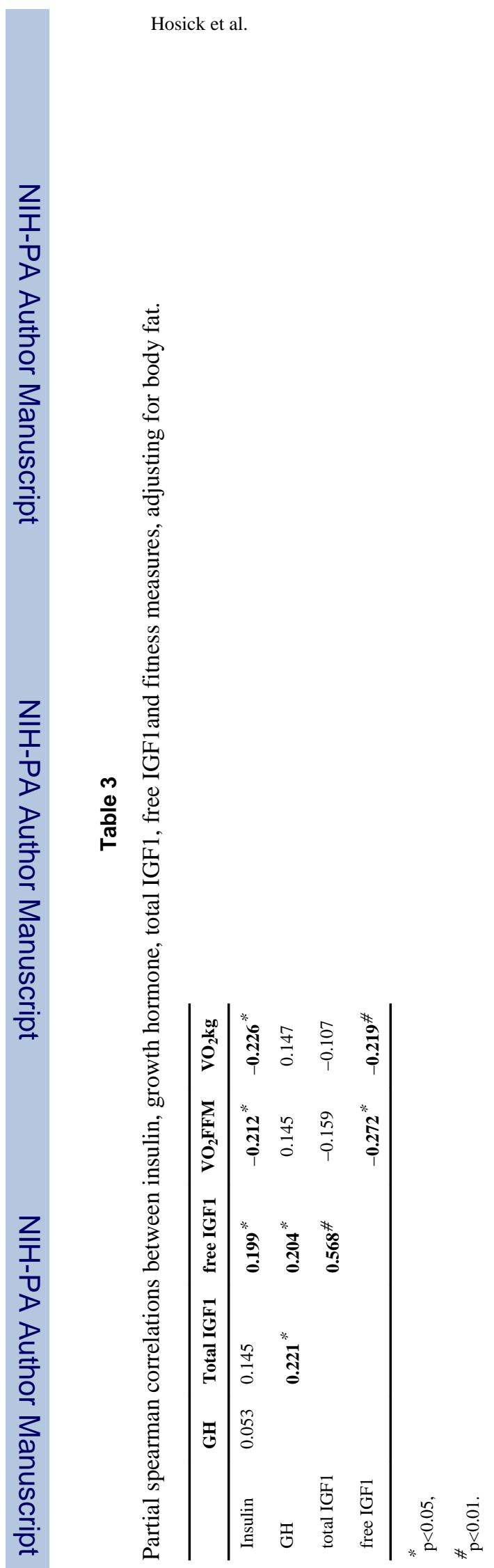

Growth Horm IGF Res. Author manuscript; available in PMC 2013 April 01. 